\title{
Spinal Commissural Connections to Motoneurons Controlling the Primate Hand and Wrist
}

\author{
Demetris S. Soteropoulos, ${ }^{1}$ Steve A. Edgley, ${ }^{2}$ and Stuart N. Baker ${ }^{1}$ \\ ${ }^{1}$ Institute of Neuroscience, Newcastle University, Newcastle, NE2 4HH, United Kingdom, and ${ }^{2}$ Department of Physiology, Development and Neuroscience, \\ Cambridge University, Cambridge, CB2 3DY, United Kingdom
}

Left-right coordination is essential for locomotor movements and is partly mediated by spinal commissural systems. Such coordination is also essential for reaching and manipulation in primates, but the role of spinal commissural systems here has not been studied. We investigated commissural connectivity to motoneurons innervating forelimb muscles using intracellular recordings in acutely anesthetized macaque monkeys. In 57 of 81 motoneurons, synaptic responses (52 of 57 excitatory) were evoked after contralateral intraspinal microstimulation in the gray matter (cISMS; $300 \mu \mathrm{A}$ maximum current intensity). Some responses (15 of 57) occurred at latencies compatible with a monosynaptic linkage, including in motoneurons projecting to intrinsic hand muscles (9 cells). Three pieces of evidence suggest that these effects reflected the action of commissural interneurons. In two cells, preceding cISMS with stimulation of the contralateral medial brainstem descending pathways facilitated the motoneuron responses, suggesting that cISMS acted on cell bodies whose excitability was increased by descending inputs. Pairing cISMS with stimulation of the contralateral corticospinal tract yielded no evidence of response occlusion in 16 cells tested, suggesting that the effects were not merely axon reflexes generated by stimulation of corticospinal axon branches, which cross the midline. Finally, stimulation of contralateral peripheral nerves evoked responses in 28 of 52 motoneurons ( 7 of 9 projecting to the hand). Our results demonstrate the existence of commissural neurons with access to spinal motoneurons in primate cervical spinal cord that receive inputs from the periphery as well as descending pathways. Most importantly, commissural neurons also innervate motoneurons of intrinsic hand muscles.

\section{Introduction}

Bimanual interactions are required for many everyday activities, particularly in primates where coordinated movements of the two hands are frequently used for object manipulation. Multiple neural structures could contribute to this coordination across the midline. Most previous work has focused on the corpus callosum, which reciprocally connects the cerebral hemispheres (Brinkman and Kuypers, 1973; Spidalieri et al., 1986; Eliassen et al., 2000; Serrien et al., 2001; Kennerley et al., 2002; Soteropoulos and Baker, 2007), and/or on bilaterally organized cortical motor areas (Tanji et al., 1988; Kazennikov et al., 1999; Kermadi et al., 2000; Donchin et al., 2002). Subcortical centers, such as the cerebellum, reticular formation, and vestibular system, also have bilaterally organized outputs (Aoyama et al., 1971; Peterson et al., 1975; Fukushima et al., 1979; Peterson, 1979; Peterson et al., 1979; Carleton and Carpenter, 1983; Shinoda et al., 1986; Mitani et al., 1988; Soteropoulos and Baker, 2008; Zaaimi et al., 2012).

\footnotetext{
Received Jan. 15, 2013; revised Feb. 28, 2013; accepted March 11, 2013.

Author contributions: D.S.S., S.A.E., and S.N.B. designed research; D.S.S., S.A.E., and S.N.B. performed research; D.S.S., S.A.E., and S.N.B. analyzed data; D.S.S., S.A.E., and S.N.B. wrote the paper.

This work was supported by the Biotechnology and Biological Sciences Research Council, United Kingdom, and the Wellcome Trust. We thank Terri Jackson, Jo Butler, and Norman Charlton for technical assistance; Paul Flecknell and Silke Corbach-Soehle for anesthesia support; and Caroline Fox and Denise Reed for theater nursing.

The authors declare no competing financial interests.

This article is freely available online through the J Neurosci Author Open Choice option.

Correspondence should be addressed to Dr. Stuart N. Baker, Institute of Neuroscience, Henry Wellcome Building,

Framlington Place, Newcastle upon Tyne, NE2 4HH, United Kingdom. E-mail: stuart.baker@ncl.ac.uk

DOI:10.1523/JNEUROSCI.0269-13.2013

Copyright $\odot 2013$ the authors $\quad 0270-6474 / 13 / 339614-12 \$ 15.00 / 0$
}

At the spinal level, commissural interneurons (CINs) are defined by an axonal projection to the contralateral spinal cord but are richly heterogeneous in their dorsoventral location, their postsynaptic targets, and their presynaptic inputs (Bannatyne et al., 2006; Jankowska, 2008). CINs can contact contralateral (and ipsilateral) motoneurons directly (Jankowska et al., 2009) as well as premotor interneurons (Bajwa et al., 1992; Edgley et al., 2003; Jankowska et al., 2005a, 2005b, 2006). CINs can exert either excitatory (glutamatergic) or inhibitory (glycinergic) actions (Bannatyne et al., 2003, 2009; Stecina et al., 2008; Jankowska et al., 2009), and outputs may be under serorotinergic and noradrenergic influence (Hammar et al., 2004, 2007).

The best-studied spinal commissural systems are in the cat spinal cord, where they coordinate bilateral reflexes and locomotion as well as relay signals from descending pathways. One group comprises CINs in the upper cervical cord (C1-C3) with a role in bilaterally organized vestibulocollic reflexes (Sugiuchi et al., 1992; Endo et al., 1994). Another group, located in C3-C5 segments is thought to mediate hindlimb postural adjustments associated with forelimb reaching (Alstermark and Kummel, 1990). The best-described group are in the lumbar cord, where they receive direct reticulospinal inputs and excite or inhibit contralateral motoneurons (Bannatyne et al., 2003; Jankowska et al., 2003; Edgley et al., 2004; Hammar et al., 2007). As reticulospinal systems are also involved in voluntary forelimb movements in both cats and primates (Prentice and Drew, 2001; Buford and Davidson, 2004; Schepens and Drew, 2004, 2006; Riddle et al., 2009; Riddle and Baker, 2010; Soteropoulos et al., 2012), if similar 
CINs are also present in primate lower cervical cord, they could provide a segmental-level system for arm and hand coordination across the midline.

Here we address whether CINs exist in the primate cervical cord. By measuring inputs to identified macaque forelimb motoneurons after intraspinal microstimulation (cISMS) of contralateral spinal circuits, we show that a system of CINs with access to forearm as well as intrinsic hand motoneurons exists in the primate cervical cord.

\section{Materials and Methods}

All animal procedures were performed under United Kingdom Home Office regulations in accordance with the Animals Scientific Procedures Act (1986) and were approved by the Local Research Ethics Committee of Newcastle University. Recordings were made from five terminally anesthetized female rhesus macaque monkeys (coded FY, JN, JW, JD, and UR in this report; age 12, 9, 9, 9, and 14 years, respectively; weight 8.2, $6.0,9.2,7.6$, and $11.0 \mathrm{~kg}$, respectively). Data from these animals were also used in other previous publications (Soteropoulos et al., 2011; Zaaimi et al., 2012).

Surgical preparation. Animals were initially sedated by intramuscular injection of ketamine $(10 \mathrm{mg} / \mathrm{kg})$; then deep anesthesia was induced with propofol (5-14 $\mathrm{mg} \mathrm{kg}^{-1} \mathrm{~h}^{-1}$, i.v.). A tracheotomy was performed, and anesthesia switched to sevoflurane inhalation (3-5\%) and an intravenous infusion of alfentanil $\left(7-23 \mu \mathrm{g} / \mathrm{kg}^{\prime} \mathrm{h}\right)$ with artificial ventilation; this regimen was used to complete all major surgery. Central arterial and venous lines were inserted via the external carotid artery and external jugular vein. The bladder was catheterized. Peripheral nerves were exposed by dissection, and nerve cuff electrodes placed bilaterally around the median and ulnar nerves in the arm and the deep radial nerve just proximal to the cubital fossa, and on the right side only around the medial and ulnar nerves at the wrist. For monkey UR, more proximal nerve stimulation was achieved by also placing a nerve cuff on the right radial nerve at the axilla and inserting two multistranded stainless steel wires (overall external diameter $0.15 \mathrm{~mm}$; Teflon insulation bared for a few millimeters at the tip) percutaneously in the vicinity of Erb's point. A laminectomy was then made exposing spinal segments C6-T1. The head was fixed in a stereotaxic frame, angled to produce $\sim 60^{\circ}$ neck flexion, and the spinal column was supported by vertebral clamps at high thoracic and mid-lumbar vertebrae. A bilateral pneumothorax was made. The anesthetic regimen was then switched to intravenous infusions of propofol $(5-14 \mathrm{mg} / \mathrm{kg} / \mathrm{h}$ ) and alfentanil (dose as above); we have previously found that this regimen increases the excitability of the CNS, making it more appropriate for electrophysiological recordings than the inhalation anesthetic used during surgical preparation. Neuromuscular blockade was initiated (atracurium, $0.7 \mu \mathrm{g} / \mathrm{kg} / \mathrm{h}$ ). Inspired oxygen concentration was reduced to $\sim 50 \%$ to avoid complications of oxygen toxicity consequent on long-term anesthesia. Fluid balance was maintained by infusion of Hartman's solution (to give a total infusion rate of $5 \mathrm{ml} / \mathrm{kg} / \mathrm{h}$, including drug infusions). CNS edema was minimized by administration of methylprednisolone (initial loading dose $30 \mathrm{mg} / \mathrm{kg}$ i.v., followed by infusion of $5.4 \mathrm{mg} / \mathrm{kg} / \mathrm{h}$ i.v.). The animal was heated via a thermostatically controlled pad, and a blanket supplied with warm air. Throughout all surgery and experimental procedures, the animal's physiological condition and anesthetic level were ensured by continually monitoring endtidal $\mathrm{CO}_{2}$ concentration, oxygen saturation, rectal and skin temperature, central arterial and venous blood pressure, and heart rate. Slowly rising trends in heart rate or arterial blood pressure were taken as evidence of waning anesthesia, and drug infusion rates were adjusted accordingly. Throughout the experiment, peripheral nerve stimuli were given that would have provoked rapid changes in heart rate and blood pressure in the absence of adequate anesthesia and analgesia. Monitoring whether such changes were seen provided an additional indicator for adjusting the continual anesthetic infusions.

Stimulation. Stainless steel stimulating electrodes (MS501G, Microprobe) were implanted into the left and right medullary pyramidal tracts (PT, monkeys JW, JD, and JN) and left and right medial longitudinal fasciculus (MLF, monkeys FY, JW, JD, and JN) using a double-angle stereotaxic technique (Soteropoulos and Baker, 2006). PT electrodes were positioned with reference to antidromic volleys recorded epidurally from motor cortex (craniotomy centered at A18, ML13) after stimulation through them, in combination with orthodromic volleys recorded from the spinal cord dorsal surface. Motor cortical antidromic volleys were recorded bilaterally, so that optimization of the PT electrode position included checking that stimulus currents of $300 \mu \mathrm{A}$ (biphasic stimuli, $0.2 \mathrm{~ms}$ per phase) evoked recordable volleys only in the ipsilateral motor cortex. MLF electrodes were positioned to yield a spinal volley at the lowest threshold, with no antidromic motor cortex volley. Occlusion tests were performed by combining stimuli of both left and right PT electrodes with the MLF electrodes on either side; these confirmed that the different electrodes activated nonoverlapping populations of descending fibers (Fig. 1A-F). The indifferent electrode for all stimuli was a silver wire electrode inserted under the scalp.

Spinal stimulation used 4-7 electrodes, inserted on the left side of the exposed cord after opening the spinal dura. Electrodes were spaced $\sim 2-3$ $\mathrm{mm}$ apart in the rostrocaudal direction and were $\sim 1.5 \mathrm{~mm}$ from the midline. Electrodes either comprised $50-\mu \mathrm{m}$-diameter Teflon-insulated stainless steel wires or short lengths of parylene-insulated stainless steel microelectrodes (MS501G, Microprobes) joined to multistranded insulated stainless steel wire; the electrode-wire junction was insulated with epoxy cement. Electrodes were inserted by hand using fine forceps to a depth of 3-4 $\mathrm{mm}$ below the cord surface and positioned to maximize evoked volleys recorded from the peripheral nerve cuffs on the left side; tissue glue (Indermil, Henkel) was then used to relieve strain in the connecting wire and to fix the electrode to an adjacent vertebra.

Isolated constant-current stimulators (model 2100, AM Systems) were used to deliver all stimuli.

Motoneuron recordings. Intracellular recordings were made from spinal motoneurons using sharp glass micropipettes (tip impedance 3-20 $\mathrm{M} \Omega$ ) filled with $2 \mathrm{~m}$ potassium acetate, inserted into the ventral horn of the spinal cord through small patches made in the arachnoid and pia. Motoneurons were antidromically identified if they could be fired after stimulation of the right-sided nerve cuffs (intensity $3 \times$ motor threshold, determined before the onset of neuromuscular blockade). The identity of cuffs to which the motoneuron responded, combined with known anatomy, allowed determination of the muscle group to which it projected (upper arm extensors, forearm flexors or extensors, intrinsic hand muscles). After identification, synaptic responses were recorded after cISMS, and stimulation through PT and MLF electrodes (stimulus intensity up to $300 \mu \mathrm{A}$ biphasic pulses, $0.2 \mathrm{~ms}$ per phase, trains of 1 , 3 , or 4 stimuli at interstimulus intervals of $3 \mathrm{~ms}, 1 \mathrm{~Hz}$ repetition rate). In stable recordings, where there was full invasion of antidromic action potentials and no decline or ventilation-associated changes in membrane voltage after initial testing and where responses to cISMS/brainstem were stable upon repeated stimuli, we also measured the effects of preceding the cISMS with PT/MLF stimulation; one or three stimuli to the brainstem electrode (3 ms interstimulus interval within the train of three) were delivered $3 \mathrm{~ms}$ before cISMS.

During all recordings, a silver ball electrode on the cord dorsum close to the site of electrode penetration recorded surface volleys. Intracellular waveforms (gain 200 or 500, bandpass $10 \mathrm{~Hz}$ to $10 \mathrm{kHz}$, sampling rate $25 \mathrm{kHz}$ ), spinal and M1 surface recordings (gain $10 \mathrm{~K}$, bandpass $30 \mathrm{~Hz}$ to $5 \mathrm{kHz}$, sampling rate $12.5 \mathrm{kHz}$ ), and stimulus markers were sampled using a micro1401 interface and Spike2 software (Cambridge Electronic Design).

Histology. At the end of each experiment, marker lesions were generated at each spinal and brainstem stimulating electrode by passing currents of $50-100 \mu \mathrm{A}$ for $20 \mathrm{~s}$ (electrode negative). Anesthesia was then increased to a lethal level, and animals were perfused through the heart with PBS followed by $4 \%$ paraformaldehyde in saline. Brains and spinal cords were removed, and after postfixation and cryoprotection in sucrose (final concentration $30 \%$ ), sectioned at $80 \mu \mathrm{m}$ on a freezing microtome. Sections were mounted and stained with cresyl violet before reconstruction of the location of stimulating electrode tips in the brainstem and spinal cord. Spinal sections for three monkeys, indicating the location of stimulating electrode tips, are shown in Figure $1 G$.

Analysis. Postsynaptic responses in motoneurons were identified from both superimposed single sweeps and averaged intracellular records. 


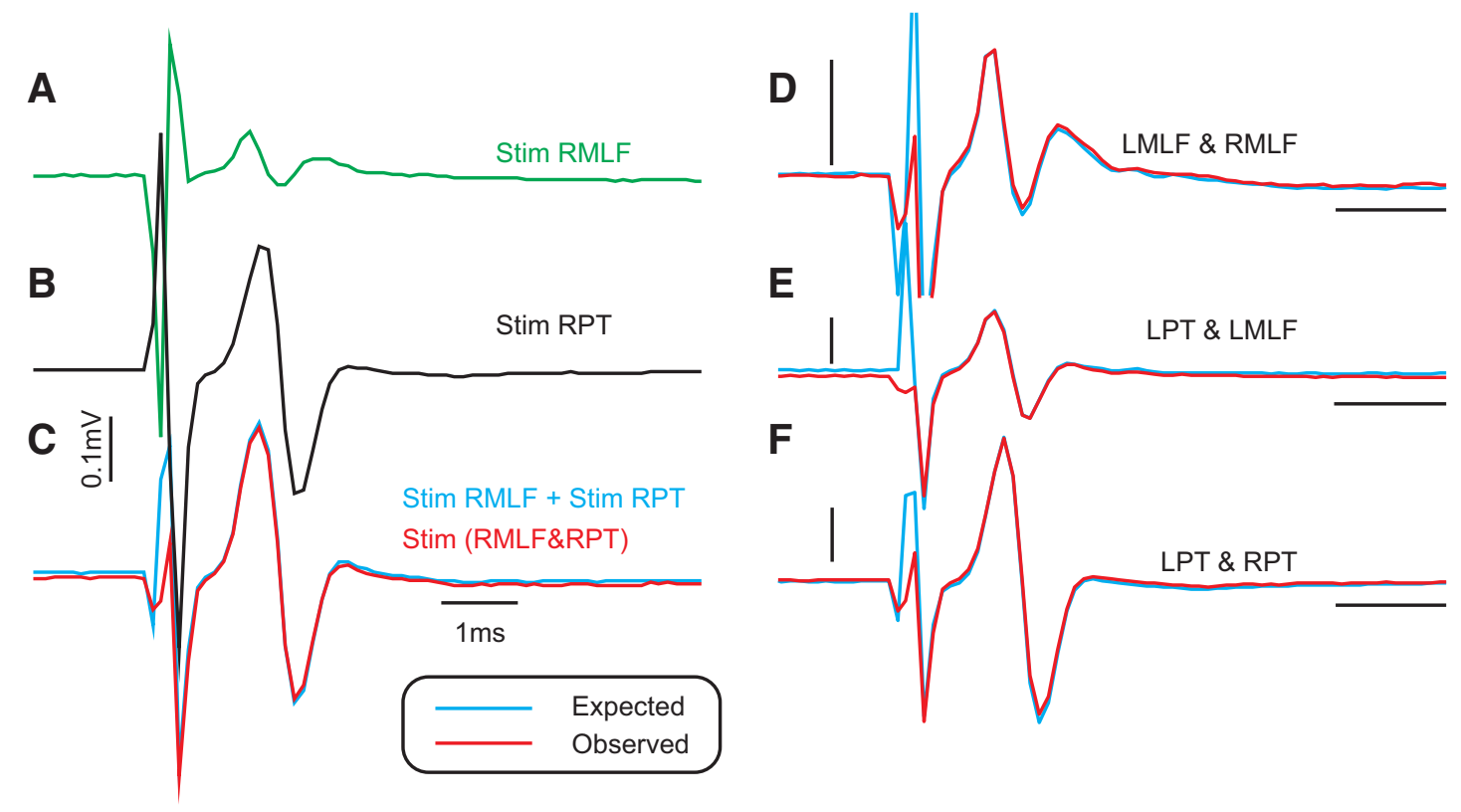

G
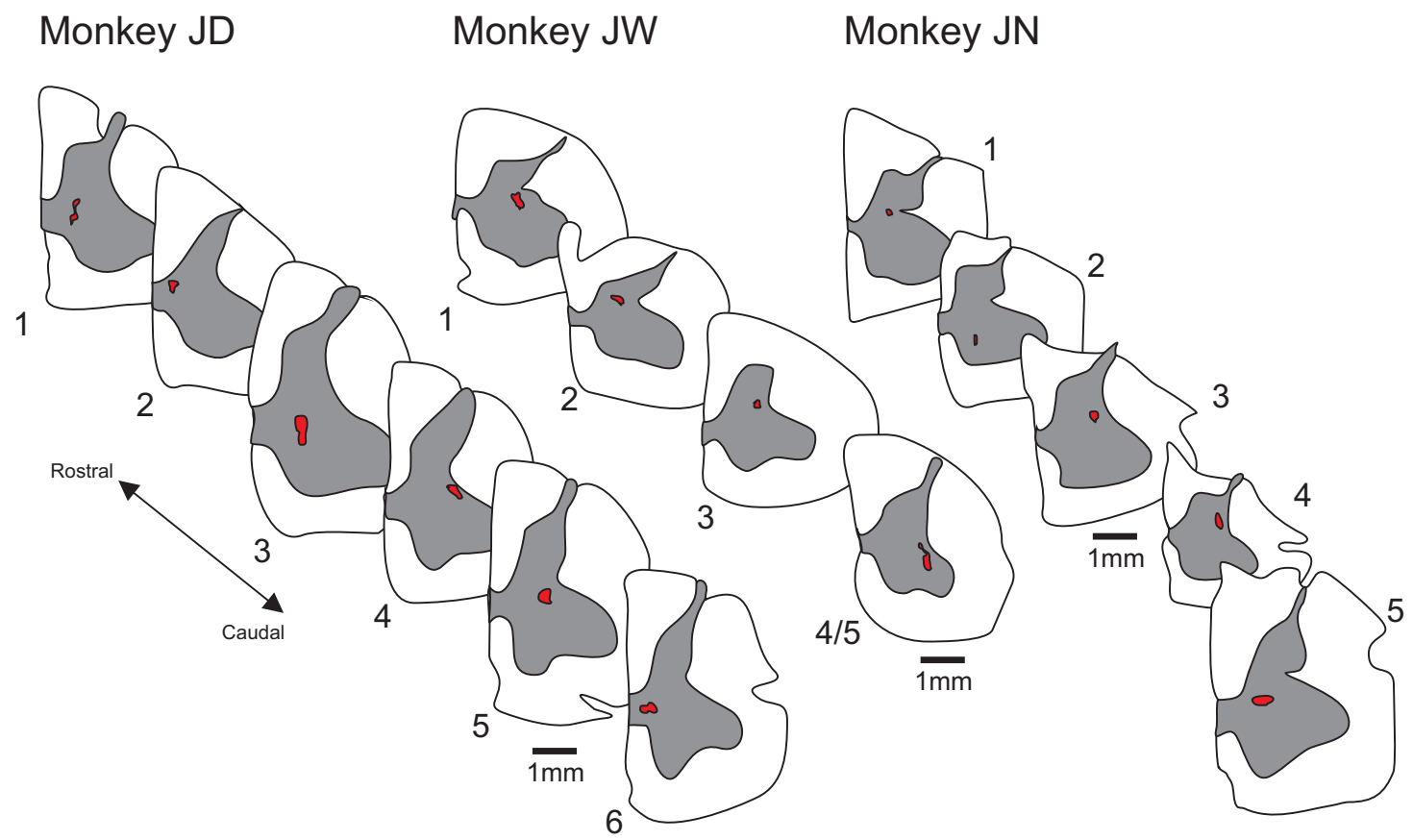

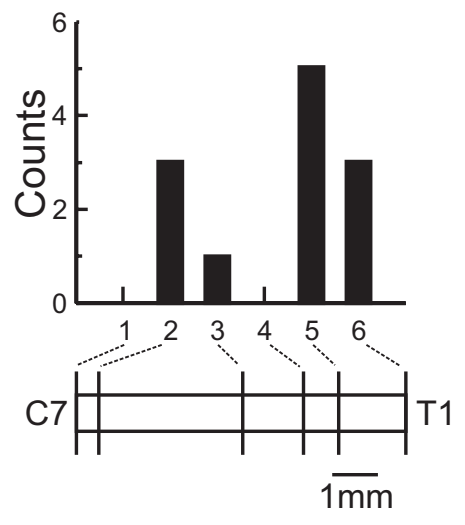

Stimulation Site

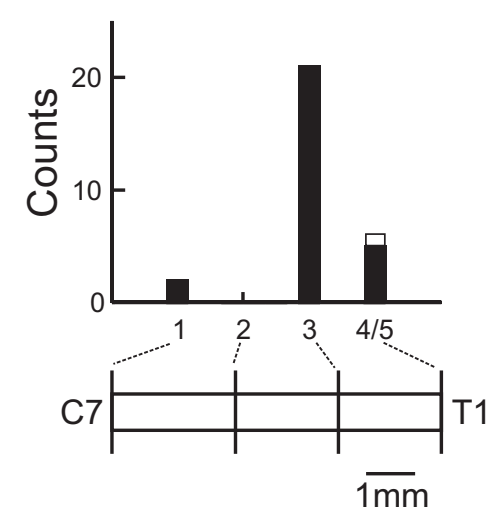

Stimulation Site

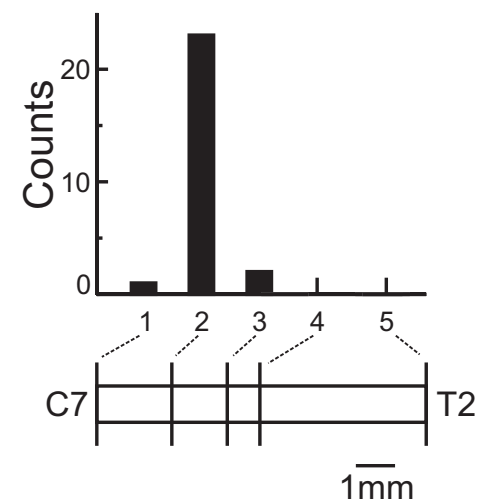

Stimulation Site 

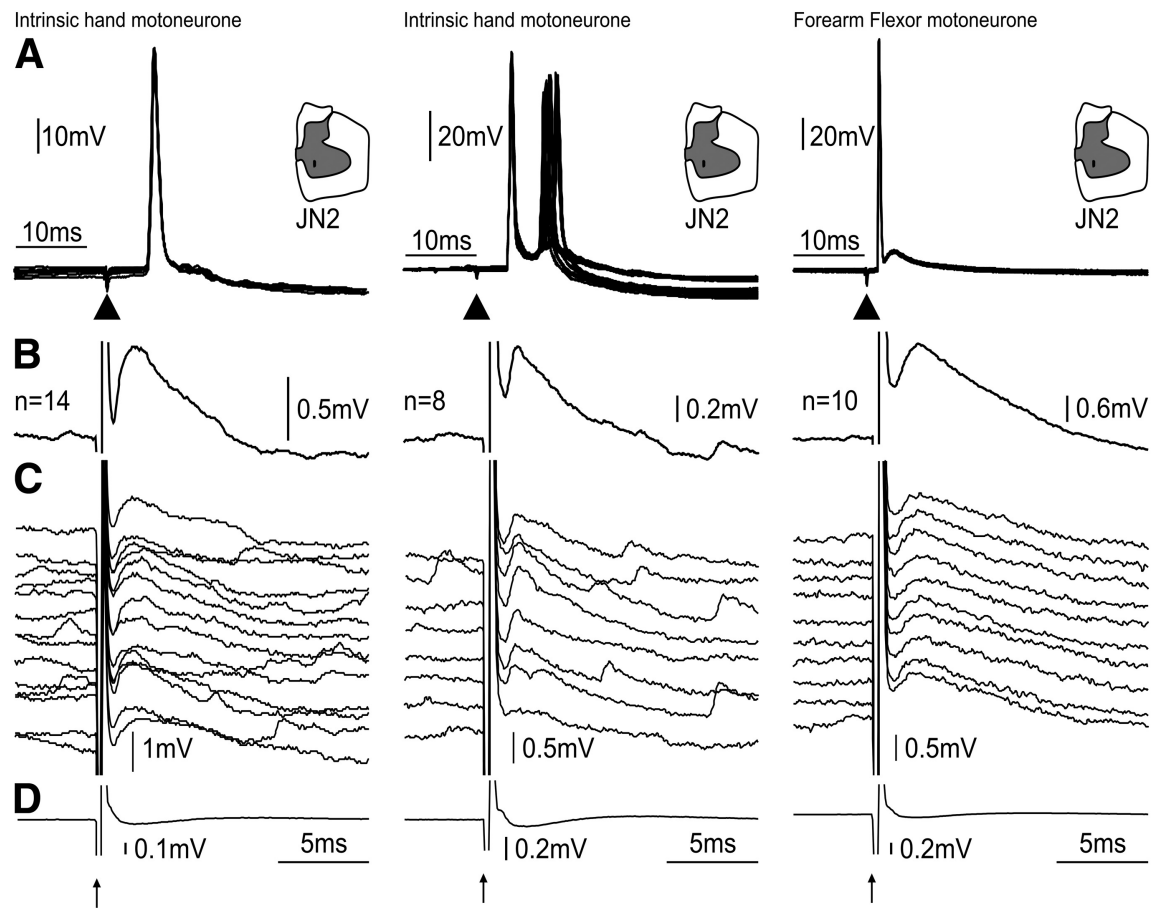

Figure 2. Example intracellular responses to contralateral intraspinal stimulation. Three motoneurons recorded in the same experiment are illustrated, identified as projecting to the muscle groups labeled at the top of each column. $A$, Antidromic activation from peripheral nerve. The motoneuron in the central panel shows both antidromic and subsequent orthodromic spikes. $\boldsymbol{B}$, Mean intracellular response to contralateral intraspinal microstimulation $(100,180$, and $200 \mu$ A stimulus currents, respectively). $C$, Single-sweep intracellular potentials that contributed to the averages in $\boldsymbol{B}$. D. Averaged cord dorsum potential responses recorded simultaneously as $\boldsymbol{B}$. Arrows indicate time of stimulation.

Conventionally, spinal segmental latencies are measured from the onset of the surface volley, which indicates the arrival time of axonal action potentials in that region of the cord, to the onset of postsynaptic potentials (PSPs). For responses to cISMS, the large stimulus artifact obscured the onset of the volley. We thus report "raw" latencies for these PSPs relative to stimulus onset, and consider latencies $\leq 1.2 \mathrm{~ms}$ to reflect monosynaptic inputs (allowing minimally $0.5 \mathrm{~ms}$ for synaptic transmission and $0.2 \mathrm{~ms}$ stimulus utilization time, with an unknown central conduction time: disynaptic actions would require 2 synaptic delays plus the utilization time: $2 \times 0.5+0.2 \mathrm{~ms}=1.2 \mathrm{~ms}$ ). PSP amplitudes were measured from the onset to peak.

Significance testing of conditioning effects. To test whether there was an effect from the conditioning stimulus, we checked whether the conditioning paradigm caused any effect that could not be predicted from

\section{$\leftarrow$}

Figure 1. Confirmation of the systems activated by electrical stimulation. $A-F$, Cord dorsum recordings of responses to brainstem stimulation. $\boldsymbol{A}$, Response evoked by stimulation of the right MLF. $B$, Response evoked by stimulation of the right PT. C, Response evoked by simultaneous stimulation of both right PT and right MLF (red trace) superimposed on the sum of responses in $\boldsymbol{A}, \boldsymbol{B}$ (blue trace). $\boldsymbol{D}$, Same as in $\boldsymbol{C}$ but for combined stimulation of left and right MLF. $E$, Same as in C but for combined stimulation of left MLF and left PT. $F$, Same as in C but for combined stimulation of right and left PT. Stimulation intensity for PT/MLF was at $300 \mu \mathrm{A}$. G, Locations of intraspinal stimulating electrode tips in cervical spinal cord based on histological reconstructions of electrolytic lesions (red). Sections are shown for three experiments, which provided 72 of 81 of the motoneurons analyzed. The histograms underneath show the distribution of effects evoked and analyzed further from each electrode. The horizontal bars represent the relative distance between the electrodes, whereas the approximate segmental levels at the rostralmost and caudalmost electrodes are labeled. For monkey JW, the two most caudal intraspinal electrode tips were very close together, and it was not possible to separate the lesions. Accordingly, only one spinal section is shown (labeled 4/5). In subsequent figures, where possible, an inset figure is shown next to each response to indicate the location of the intraspinal electrode eliciting the response, labeled as in this panel. summing the responses to cISMS and brainstem stimuli alone. First, the mean responses were generated by averaging across the stimulus presentations for each different stimulus condition, leading to three averages ( cISMS $_{\text {only }}$, Brainstem $_{\text {only }}$, cISMS $_{\text {conditioned }}$ ). The mean membrane voltage during a response region selected by the experimenter (typically $4 \mathrm{~ms}$ long, range: $0.5-10 \mathrm{~ms}$ ) was calculated for each stimulus condition. The "net conditioning effect" was calculated as the difference between cISMS only $_{\text {and }}$ cISMS condi $_{\text {- }}$ tioned after taking into account any responses

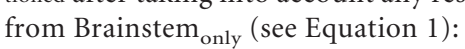

$$
\begin{aligned}
& \text { Conditioning effect }=\text { cISMS }_{\text {only }} \\
& -\left(\text { cISMS }_{\text {conditioned }}-\text { Brainstem }_{\text {only }}\right)
\end{aligned}
$$

If the stimuli did not interact, the conditioning effect should be zero. To estimate reliable confidence intervals for the given dataset available for each motoneuron, a bootstrapping approach (with replacement) was used. As the mean response type for a given condition was an average of individual stimulus presentations, a bootstrapped mean response was constructed from a random selection of the same number of individual responses as in the original dataset. This was done for all three stimulus conditions. The net conditioning effect of the bootstrapped responses was calculated using the same formula as above. This was repeated 1000 times to generate confidence intervals for the net effect. If the $95 \%$ confident intervals did not include zero, this was then considered as a significant conditioning effect $(p<0.05)$.

\section{Results}

\section{Excitatory responses to cISMS stimulation}

We were able to record the responses to stimulation of at least one contralateral stimulating site in 81 motoneurons across four monkeys (FY, 9; JW, 34; JD, 13; JN, 25). The most common response was a short latency excitatory EPSP; three examples from different motoneurons are shown in Figure 2. Figure $2 \mathrm{~A}$ shows antidromic spikes elicited by the most distal nerve to which each cell responded. Two cells were activated from the ulnar nerve at the wrist, identifying their targets as intrinsic hand muscles. One cell was activated antidromically from the median nerve in the arm, but not the wrist, indicating that it projected to a forearm flexor muscle. Figure $2 B$ shows averaged potentials, and Figure $2 C$ single-sweep responses, to cISMS stimulation. In all three cells, short-latency EPSPs were evoked (onset latencies 1.07, 1.27 , and $1.38 \mathrm{~ms}$, respectively). Recordings to identical stimuli made shortly after the electrode was withdrawn from the cell did not show any comparable waveforms, confirming the intracellular synaptic nature of these potentials. Figure $2 D$ illustrates the simultaneously recorded cord dorsum potentials.

Figure 3 presents population data on the responses evoked by cISMS. Inevitably, we did not sample all motoneuron groups equally (Fig. $3 A$ ); most common were recordings from forearm flexor motoneurons (activated antidromically from the median or ulnar nerves at the arm, but not the wrist; 58\%), followed by intrinsic hand muscle motoneurons (median or ulnar nerve at the wrist; 28\%) and forearm extensor motoneurons (deep radial nerve; $14 \%$ ). Across the population of motoneurons tested with cISMS, 53 were tested with both single and triple stimuli, 6 with 
A

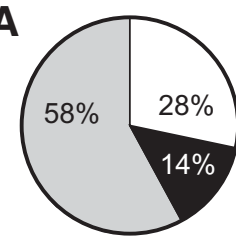

MN Incidence(81)
B

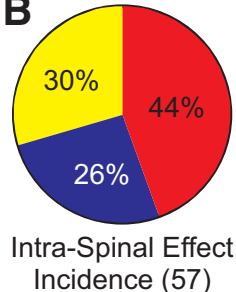

Incidence (57)

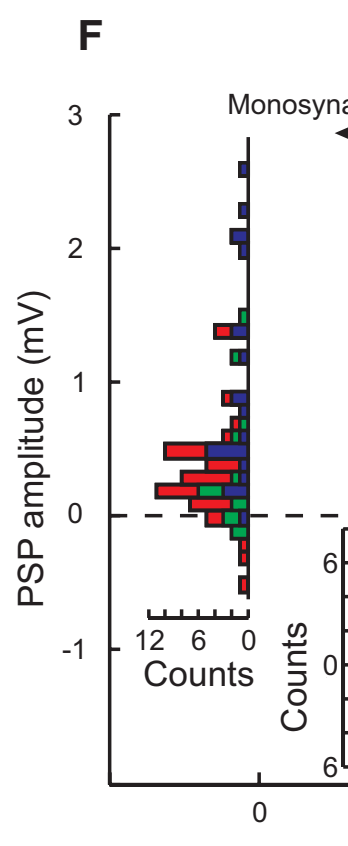

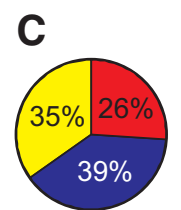

Distal Hand (23)
D

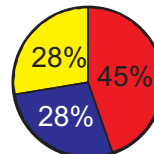

Forearm Flx.(47)
E

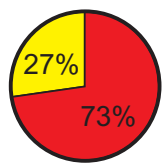

Forearm Ext. (11)

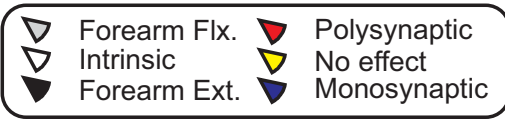

1 stimulus (latency $<=1.2 \mathrm{~ms}$ )

1 stimulus (latency $>1.2 \mathrm{~ms}$ )

- 3 stimuli

Figure 3. Population data on motoneuron responses to contralateral intraspinal stimulation. $\boldsymbol{A}$, Proportions of motoneurons sampled, which projected to different muscle categories. $\boldsymbol{B}$, Proportions of motoneurons that responded to cISMS. $\boldsymbol{C}-\boldsymbol{E}$, Same as in $\boldsymbol{B}$ but compiled separately for motoneurons projecting to the different muscle groups. $\boldsymbol{F}$, Scatter plot of response amplitude versus response latency. Symbol colors represent monosynaptic EPSPs (blue), polysynaptic EPSPs evoked by single stimuli (green, on basis of latency $>1.2 \mathrm{~ms}$ ), and polysynaptic EPSPs evoked by trains of stimuli (small red symbols, based on a lack of responses to single stimuli). The horizontal and vertical histograms indicate the distribution of latencies and amplitudes, respectively, with bars coded using the same color scheme.

only single shock, and 22 with only triple shock. The average number of sweeps available to assess each cISMS effect was 23 (range, 5-181). In cases where cISMS at multiple sites was tested in a given motoneuron and multiple effects were found, the effect with the shortest latency was the one included in this population analysis. Responses to single stimuli with latencies shorter than 1.2 ms were considered to be monosynaptic, those with latencies $>1.2 \mathrm{~ms}$ or where single stimuli were ineffective but responses were evoked by trains of three stimuli were considered polysynaptic; effects for which we did not deliver a single stimulus were assumed to be polysynaptic.

This conservative approach can identify some, but not necessarily all, responses where our intraspinal stimuli activated directly neurons that made monosynaptic connections with contralateral motoneurons. The objective here was to determine whether spinal commissural neurons connect with motoneurons. Responses showing temporal summation need not necessarily be disynaptic if the first stimulus is subthreshold to activate a neuron or axon. Latencies $>1.2$ ms could be monosynaptically mediated via more slowly conducting axons and terminals. However, the presence of some unequivocal monosynaptic EPSPs establishes the principle that intraspinal stimuli can evoke them.

Seventy percent of motoneurons tested responded to cISMS stimulation; $26 \%$ responded at a monosynaptic latency (Fig. 3B).
Similar proportions were seen when analysis was performed separately for intrinsic hand and forearm flexor motoneurons (Fig. $3 C, D)$. By contrast, although the overall proportion of responding forearm extensor motoneurons was similar (73\%), none of these responses met our criterion for monosynaptic PSPs. This result should however be treated with caution, given the small number $(n=11)$ of wrist or digit extensor motoneurons in our dataset.

Figure $3 F$ plots the response latency versus amplitude for all effects evoked by intraspinal stimulation. Different colored circles identify monosynaptic EPSPs (blue), PSPs evoked by single stimuli at what is considered polysynaptic latency $(>1.2 \mathrm{~ms}$; green), and PSPs considered to be polysynaptic based on being evoked by three stimuli but not a single one (red). The vertical dotted line at $1.2 \mathrm{~ms}$ indicates our cutoff criterion for monosynaptic versus polysynaptic effects. A histogram of the response latencies is shown under the abscissa.

The overall mean \pm SD latency for EPSPs evoked by cISMS stimulation was $1.41 \pm 0.45 \mathrm{~ms}$, and the mean \pm SD amplitude of EPSPs was $0.69 \pm 0.62 \mathrm{mV}$; the distribution of PSP amplitudes is also shown as a histogram in Figure $3 F$, alongside the ordinate axis. Monosynaptic EPSPs evoked by cISMS stimulation (mean $\pm \mathrm{SD}, 1.1 \pm 0.75 \mathrm{mV}$ ) were significantly larger than polysynaptic effects (mean $\pm \mathrm{SD}, 0.42 \pm 0.34 \mathrm{mV}$, 


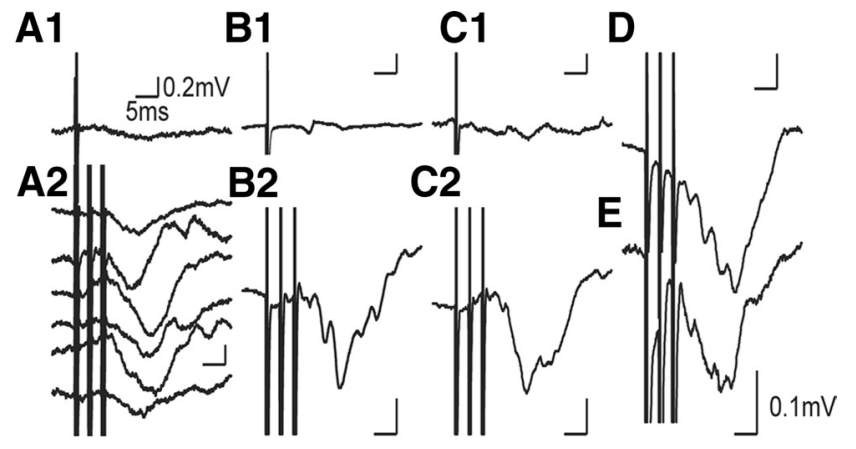

$\mathbf{F}$
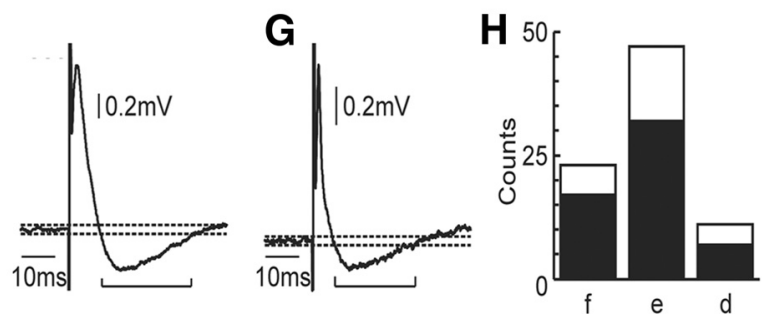

Figure 4. Inhibitory responses to contralateral intraspinal stimulation. $\boldsymbol{A}-\boldsymbol{E}$, Averaged responses in five different motoneurons to CISMS stimulation. $\boldsymbol{A}-\boldsymbol{C}$, Responses in three different motoneurons in which single stimuli did not evoke consistent responses $(\boldsymbol{A} \mathbf{1}, \boldsymbol{B} \mathbf{1}, \mathbf{C} \boldsymbol{1})$, but IPSPs were evoked by trains of three stimuli $(\boldsymbol{A 2}, \boldsymbol{B} \mathbf{2}, \mathbf{C} 2)$. In motoneuron $\boldsymbol{A} \mathbf{1}$, all six contralateral sites tested evoked IPSPS (all six averages are shown). D, $\boldsymbol{E}$, Cells were not tested with single shock stimulation. $\boldsymbol{F}, \boldsymbol{G}$, Responses in two example motoneurons in which single cISMS stimuli evoked EPSPs that declined sharply to below the resting potential, suggesting that IPSPs as well as EPSPs were evoked. Dotted horizontal lines show potentials \pm 3 SD of the prestimulus membrane potential; the potential fell to a significantly hyperpolarized level after the EPSP. $\boldsymbol{H}$, Histogram indicating the fraction of tested motoneurons (total bar) showing an IPSP (black bar). Cells according to whether they project to forearm flexors (f), forearm extensors (e), or intrinsic hand muscles (d).

$p<0.01$, unpaired $t$ test). Monosynaptic connections from the corticospinal tract provide an important and well-established synaptic input to primate forelimb motoneurons. In $38 \mathrm{mo}-$ toneurons, we also tested responses to stimulation of the contralateral PT (cPT, $300 \mu \mathrm{A})$, which had mean amplitudes of $1.05 \pm 1.9 \mathrm{mV}$. There was no significant difference between the amplitudes of monosynaptic EPSPs evoked from cISMS and cPT stimulation ( $p>0.05$, unpaired $t$ test), whereas polysynaptic EPSPs from cISMS were significantly smaller $(p<0.01$, unpaired $t$ test). A positive correlation between the amplitude of EPSPs evoked bv PT and cISMS just failed to reach significance $\left(r^{2}=\right.$ $0.14, p=0.06$ ).

\section{Inhibitory responses to cISMS}

Surprisingly, isolated IPSPs were seen in only five motoneurons $(6 \%)$ after cISMS and had long latencies. These are illustrated in Figure $4 A-D$; the amplitude and latency of these effects are included in the cluster plot of Figure $3 F$ (points with a negative amplitude). The average onset latency of the IPSP response to three stimuli was $5.5 \mathrm{~ms}$ (range, $4.5-6.1 \mathrm{~ms}$ ), and the mean IPSP size was $0.2 \mathrm{mV}$ (range, $0.08-0.45 \mathrm{mV}$ ). In two cases where IPSPs were seen after a single stimulus (Fig. 4A1,B1), the onset latencies were 7.1 and $11.4 \mathrm{~ms}$ and amplitudes 0.07 and $0.12 \mathrm{mV}$, respectively.

Although isolated IPSPs were infrequent, in many cases a rapid falling phase of the EPSPs, which often fell below the initial resting potential, suggested that cISMS evoked a mixed EPSPIPSP response. Two examples are illustrated in Figure 4F, G. Quantitative measurements of onset latency and amplitude were not feasible in these instances because any measure would be affected by both IPSP and EPSP properties. Overall, 54 motoneurons showed evidence of an IPSP after single or triple stimuli (either an EPSP falling phase, which fell below the resting potential, or an isolated IPSP). The distribution of these cells, separated by target muscle group, is shown in Figure $4 H$. The size of the evoked IPSP is dependent upon the membrane potential: for cells with no obvious inhibition, we cannot exclude the possibility that an IPSP may have been detectable at a more depolarized membrane potential.

Conditioning responses to cISMS with brainstem stimulation Intraspinal microstimulation on one side of the cord is likely to activate cell bodies and axons originating on the side of stimulation but could also activate axons that originate on the contralateral side and project to the vicinity of the stimulus site antidromically. Such axons could come from CINs, but they could also originate from descending tracts, which are known to send collaterals across the midline at segmental level, such as the corticospinal (Rosenzweig et al., 2009) and reticulospinal (Peterson et al., 1975) tracts. If any of these additionally innervate motoneurons, then they could mediate the EPSP and IPSPs we describe.

One piece of evidence that suggests that cISMS did act on CINs comes from the results of conditioning with stimulation of the contralateral brainstem. If the responses to cISMS facilitate, then the descending fibers must excite the structures activated by cISMS. We demonstrated this in two motoneurons, illustrated in Figure 5. In both cases, a train of three stimuli to the right MLF was delivered before cISMS. The top traces show the responses to cISMS alone (red), brainstem alone (green), and both together (blue). The bottom traces present a comparison between the response to cISMS alone (red) and the conditioned response with the response to brainstem stimulation alone subtracted away (black). The gray shading highlights the area selected for statistical testing. Figure 5A2, B2 shows the confidence interval distribution for the net conditioning effects, revealing that these are significant increases ( $p<0.05$, see Materials and Methods).

These observations indicate that, at least in some cases, cISMS activated commissural neurons close to their cell bodies, where the efficacy of the intraspinal stimulus could be modulated by preceding synaptic inputs to the commissural neuron. Antidromic activation of axons distant to their cell bodies would not be expected to modulate in this way.

\section{Corticospinal axon reflexes}

Previous anatomical work (Rosenzweig et al., 2009) has indicated the following: (1) the crossed corticospinal tract contains axons that project to motoneurons; and (2) it also contains axons that recross the midline at the segmental level (having crossed in the medulla before descending, they send collaterals that return to the side of their cortical origin at spinal level): these recrossing fibers terminate principally in the medial ventral gray matter (lamina VIII). Whether individual corticospinal axons make both types of connections is unknown. If so, some of the monosynaptic EPSPs evoked by cISMS could result from an axon reflex, generated by activation of these collaterals: they would simply reflect the well-known inputs to motoneurons from the contralateral corticospinal tract, rather than provide evidence for the existence of a commissural system. Even if individual axons do not both innervate motoneurons and recross, some of the polysynaptic effects could still be generated by via activation of corticospinal fibers if the recrossing axons give rise to collaterals that innervate premotor circuits before crossing. If our 

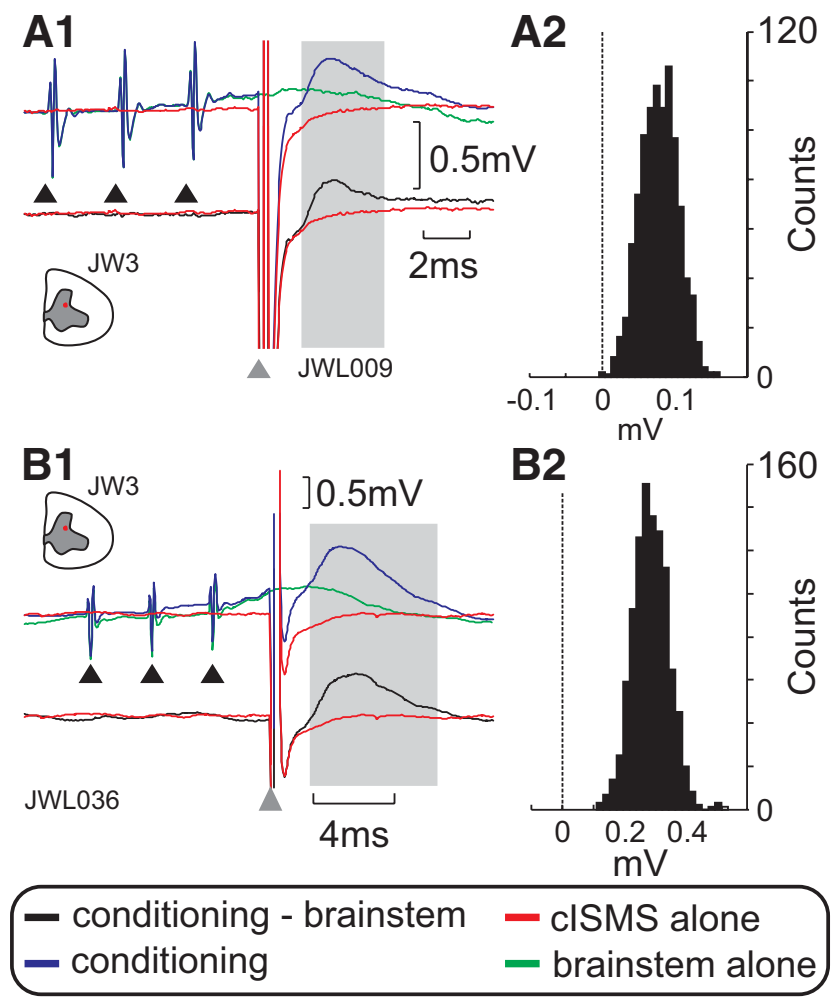

Figure 5. Facilitation of intraspinally evoked responses by interaction with MLF stimulation. $\boldsymbol{A}, \boldsymbol{B}$, Facilitation in two different motoneurons. $\boldsymbol{A} \mathbf{1}, \boldsymbol{B} \mathbf{1}$, Red trace shows response to cISMS alone $(200 \mu \mathrm{A})$; blue trace when preceded by three stimuli to the cMLF stimulation (300 $\mu \mathrm{A})$, which yielded small responses when delivered alone (green). Lower traces represent the difference between the response to combined stimulation, and to CMLF alone (black), with the response to cISMS alone overlain for comparison (red). A2, B2, Distribution of "net conditioning values" from bootstrapping analysis (see Materials and Methods). Although there were small responses to CISMS or CMLF alone, the combined stimulation produced a clear EPSP. Motoneurons were identified as projecting to the following: $\boldsymbol{A}$, a forearm extensor muscle; $\boldsymbol{B}$, a forearm flexor muscle.

results were explained by corticospinal axon reflexes in this way, cISMS and cPT stimulation would activate partially the same set of fibers. We therefore tested the effects of simultaneous stimulation of both, which should produce occlusion if common fibers are involved. A test of this type is illustrated in Figure 6A; the responses to cISMS and CPT stimulation alone are shown in red and black, respectively. The green trace shows the response when both stimuli were delivered simultaneously; the blue trace shows the linear summation of the responses to each stimulus delivered alone. The very close agreement between these two indicates that no occlusion occurred in this case and that the stimuli activated nonoverlapping neural populations. The same analysis as for the brainstem conditioning paradigms was applied to test for occlusion: if no occlusion occurs, the net effect should not be different from zero.

This test was repeated in 16 motoneurons; the difference between the response to combined cISMS and $\mathrm{CPT}$, compared with the sum of the responses to each stimulus given alone, is plotted in Figure $6 B 1$ as a function of the amplitude of the response to cISMS alone. Most values were clustered $\sim 0$, indicating no evidence for occlusion. The only case where there appeared to be a significant interaction was a facilitation (Fig. 6B1, red point). In Figure 6B2, the data are replotted. The abscissa shows the difference between the response to the combined stimuli and the sum of the individual responses, expressed as a fraction of the sum of the individual responses. The points are ordered according to mean value. There are as many points with

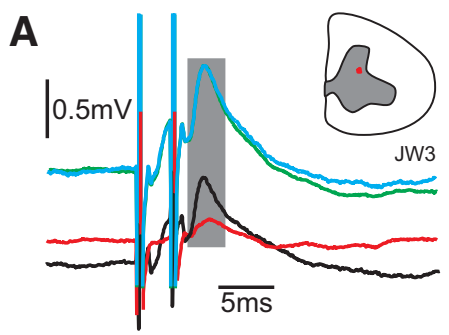

$$
\begin{aligned}
& \text { _stim. cSC only } \\
& \text { - stim. cPT only } \\
& \text { stim. cSC + cPT } \\
& \text { stim. cSC + stim. cPT }
\end{aligned}
$$

B1

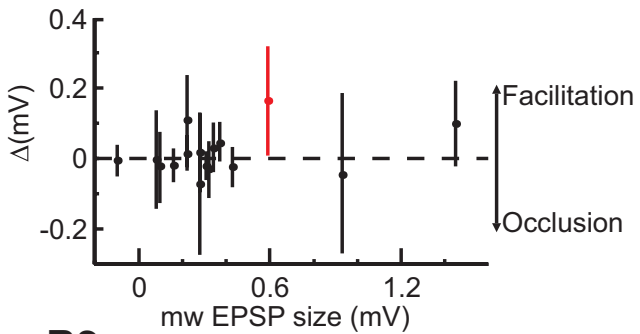

B2
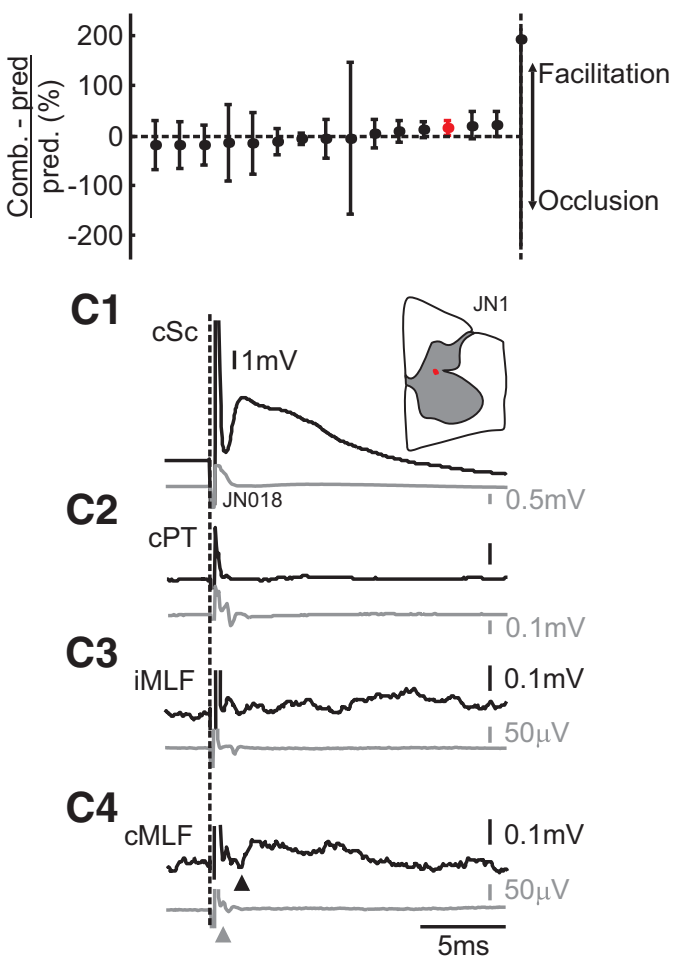

Figure 6. Lack of occlusion between responses to cISMS and contralateral corticospinal stimulation indicates that the responses are not produced by collaterals of the corticospinal tract. $A$, Example of lack of occlusion between cISMS and CPT stimulation. Green trace represents the combined response when both are stimulated together, and the blue trace represents the expected result as a linear sum of the individual responses (red represents cISMS alone; black, (PT alone). $\boldsymbol{B} 1$, Plot of difference between the combined response and sum of individual responses versus amplitude of the EPSP evoked by cISMS. In 16 MNs, no significant occlusion was seen; in one, there was facilitation (red). $\boldsymbol{B} 2$, Same data as in $\boldsymbol{B} \mathbf{1}$ but plotted in order of net conditioning effect as a proportion of the expected effect. $\boldsymbol{B 1}, \boldsymbol{B}$, The error bars indicate \pm 2SD of net effect distribution (see Materials and Methods). The effect with the largest (but not significant) facilitation had SD values ( $\pm 350 \%$ ) that were truncated to allow visualization of the other data points. $C$, Example responses from a motoneuron with a clear EPSP response after cISMS stimulation (C1), but no response from CPT (C2), or iMLF (C3), and only a small response to CMLF stimulation ( $\mathbf{C}$, onset latency $1.1 \mathrm{~ms}$, indicated by black triangle; gray triangle represents segmental arrival of descending volley). All stimuli are given at $300 \mu \mathrm{A}$. 


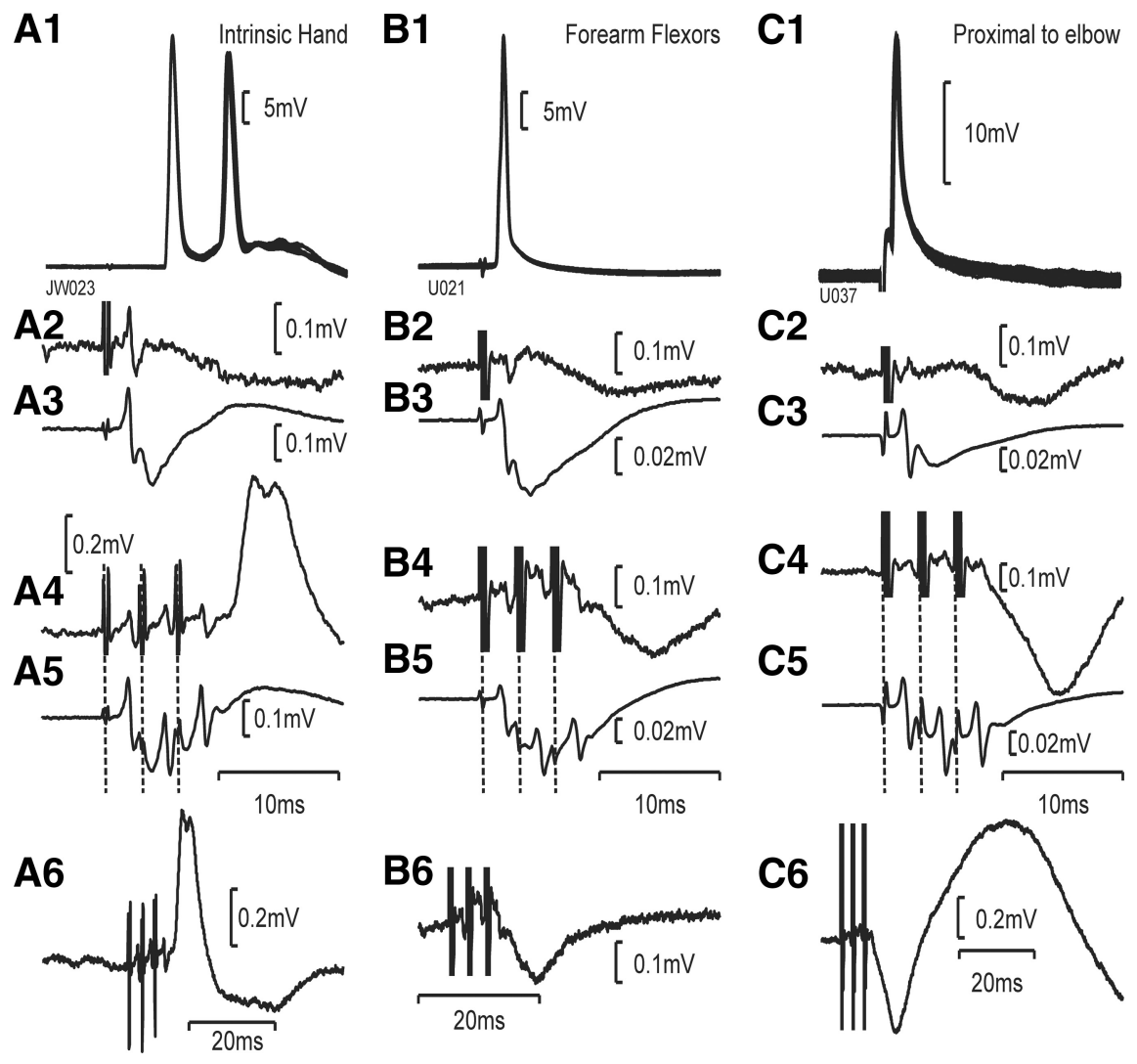

Figure 7. Example synaptic responses to contralateral peripheral nerve stimulation. $\boldsymbol{A}-\boldsymbol{C}$, Responses in three different motoneurons, projecting to an intrinsic hand muscle, a forearm flexor muscle, and a muscle proximal to the elbow, respectively. $\boldsymbol{A}$, B1, C1, Antidromic response after ipsilateral nerve stimulation (note the additional orthodromic action potential in $\mathbf{A 1}$ ). $\mathbf{A 2}, \mathbf{B 2}$, $C 2$, Intracellular response to single stimulus to a contralateral nerve. $A 3, B 3, C 3$, Simultaneously recorded cord dorsum potential. $A 4, B 4, C 4$, Synaptic response after three stimuli to the contralateral nerve. $\boldsymbol{A 5}, \boldsymbol{B} \mathbf{5}, \mathbf{C 5}$, Simultaneously recorded cord dorsum response. $\mathbf{A 6}, \boldsymbol{B} \mathbf{6}, \mathbf{C} 6$, Same as $\boldsymbol{A 5}, \boldsymbol{B 5}, \mathbf{C 5}$, but with a longer time base. Vertical dotted lines throughout indicate the times of stimulation. $\boldsymbol{A}$, Responses were to contralateral median nerve at the arm. $\boldsymbol{B}, \boldsymbol{C}$, Responses were to contralateral ulnar nerve at the arm. Stimulus intensities in all cases was $3 \times$ MT.

mean suppression as facilitation, suggesting that this mainly reflects random noise in the measurements. The sole significant effect (facilitation) may reflect summation of inputs to CINs from cPT and the intraspinal stimulus current, as already described for the other brainstem stimuli in Figure 5.

Further evidence is presented in Figure 6C. This motoneuron exhibited a large monosynaptic EPSP after cISMS (Fig. 6C1), but no response to stimulation of cPT (Fig. 6C2) or iMLF (Fig. 6C3) and only a weak EPSP from cMLF (Fig. 6C4) at a latency of 1.1 ms. This was despite the fact that the brainstem stimuli each elicited a clear descending volley (see cord dorsum recordings beneath each intracellular record in gray). In this example, the cISMS response is very unlikely to be generated by an axon reflex involving any of the descending pathways tested.

\section{Responses to contralateral nerve stimulation}

Most previously described commissural systems have inputs from peripheral afferents, but to our knowledge this has never been examined in primate hand or wrist motoneurons. We therefore investigated the effects of stimulating contralateral peripheral afferents at strengths that would activate large myelinated fibers. We examined responses to single stimuli in 15 motoneurons and to trains of three stimuli in 52 motoneurons (target muscles: intrinsic hand, 9; forearm extensor, 13; forearm flexors,
27; proximal, 3). We did not find monosynaptic responses to single stimuli in any cell but did observe responses to trains.

Example responses from three cells are illustrated in Figure 7. The motoneuron illustrated in Figure 7A1 was antidromically activated from the median nerve at the wrist (followed by a second, orthodromically evoked spike), confirming that it projected to the thenar hand muscles. Figure 7A2 shows the intracellular response to a single stimulus to the contralateral median nerve at the arm, with the cord dorsum recording (Fig. 7A3): a small deviation in the intracellular potential mirrors the cord dorsum response and represents an extracellular field potential. Figure 7A4 shows that a large EPSP was evoked by three stimuli to the same contralateral nerve with a segmental latency of $2.4 \mathrm{~ms}$ from the third stimulus (Fig. 7A5 is the corresponding cord dorsum potential). Figure $7 A 6$ shows the response on a longer time scale, revealing that the EPSP was followed by an IPSP lasting tens of milliseconds.

Figure $7 B$ illustrates responses in a forearm flexor motoneuron. In this case, a train of three stimuli delivered to the contralateral ulnar nerve at the arm produced a very clear IPSP, with a segmental onset latency of $2.3 \mathrm{~ms}$. Figure $7 C$ illustrates recordings from a motoneuron innervating a muscle proximal to the elbow. After a train of three stimuli to the contralateral ulnar nerve at the arm, an IPSP was also generated, with an onset latency of $2.3 \mathrm{~ms}$. When plotted on a longer time scale (Fig. 7C6), it is apparent that the IPSP was followed by a long-lasting EPSP.

Figure 8 presents summary data on the contralateral nerve responses. Figure $8 A$ shows the number of EPSP and IPSPs observed in the different classes of motoneuron. In cases with mixed responses to stimulation of a contralateral nerve (e.g., Fig. 7C), the earliest potential was considered, unless otherwise stated. Overall, responses were evoked in 28 of 52 motoneurons by stimulation of at least one contralateral nerve. In 14 cases, the motoneuron responded to more than one contralateral nerve, in which cases the response with the shortest latency was considered for population analysis. Overall, 23 IPSPs and 20 EPSPs were seen (including multiple responses within the same motoneuron from different nerves). Although only three motoneurons were recorded with muscle targets more proximal than the elbow, it is notable that all showed synaptic inputs from contralateral nerves. Importantly, even among motoneurons targeting intrinsic hand muscles, $78 \%$ (7 of 9) responded to stimulation of contralateral sensory inputs. Figure $8 A$ appears to suggest a slight tendency for motoneurons projecting to intrinsic hand muscles to receive mainly EPSPs, whereas motoneurons projecting to forearm flexors and extensors received mainly IPSPs; however, this was not significant $\left(p>0.3, \chi^{2}\right.$ test). The mean EPSP size was small, averaging $0.13 \mathrm{mV}(\mathrm{SD}, 0.13 \mathrm{mV})$, and the mean IPSP amplitude was $0.15 \mathrm{mV}$ (SD, $0.12 \mathrm{mV}$ ); these did not differ significantly (unpaired $t$ test, $p>0.05$ ). Figure $8 B$ separates the observed 
A

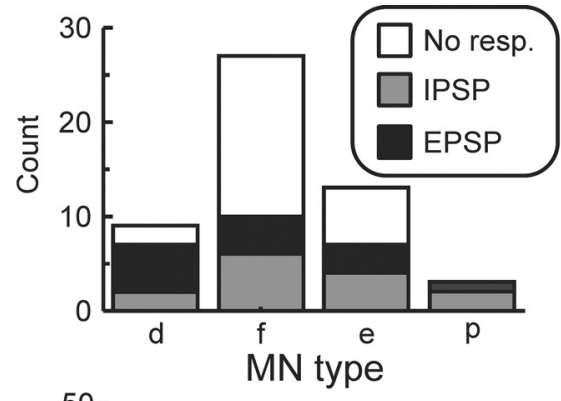

B

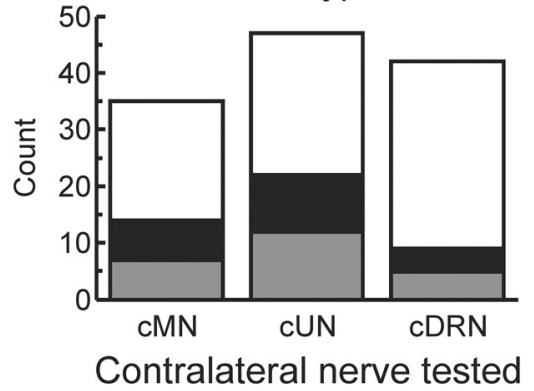

C

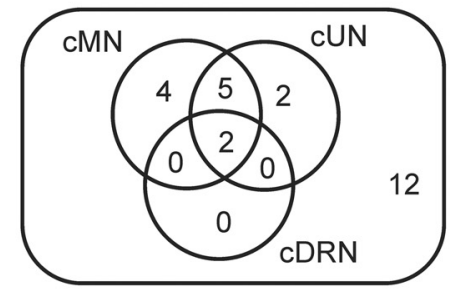

D

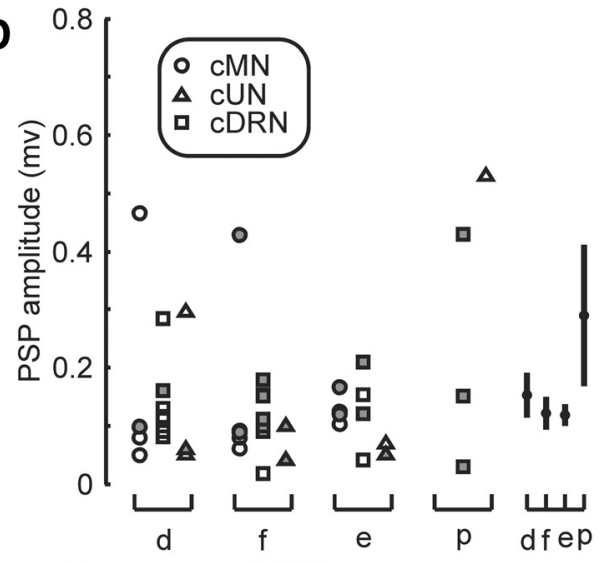

E

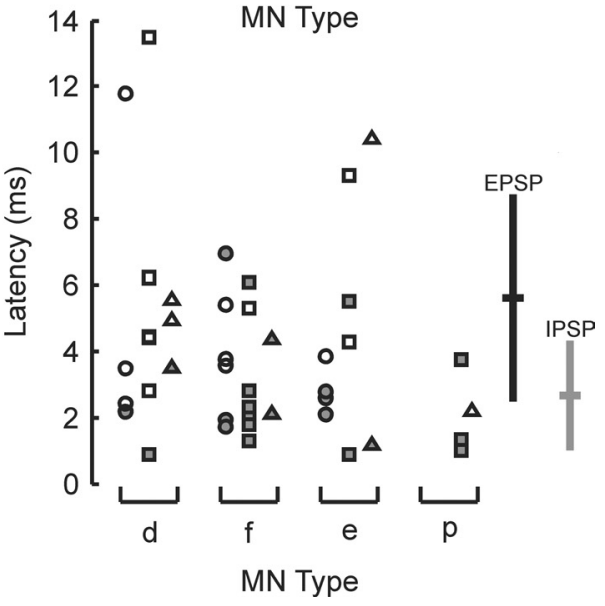

Figure 8. Population data on motoneuron responses to contralateral peripheral nerve stimulation. $\boldsymbol{A}$, Incidence of synaptic responses, separated by whether the motoneuron projected to effects according to which contralateral nerve generated them; the proportions of IPSPs and EPSPs did not differ significantly between nerves $\left(\chi^{2}, p>0.08\right)$. In 25 motoneurons, we were able to test responses to all three implanted contralateral nerves. The distribution of responses is illustrated in Figure $8 C$ as a Venn diagram. The limited numbers of responses to the deep radial nerve may represent its smaller size compared with the median and ulnar nerves.

Figure $8 D$ presents data on the amplitude of all observed effects, separated by motoneuron projection class; the cross hairs to the far right show the mean and standard mean error of the PSP amplitude for each MN class. The mean absolute PSP sizes were as follows: intrinsic hand motoneurons, $0.15 \mathrm{mV}$; forearm flexors, $0.12 \mathrm{mV}$; forearm extensors, $0.11 \mathrm{mV}$; proximal muscles, $0.29 \mathrm{mV}$. The PSPs in motoneurons projecting to proximal muscles were significantly larger than those in forearm flexor and extensor motoneurons (unpaired $t$ test, $p<0.04$ in both cases) but not from intrinsic hand muscle motoneurones $(p>0.1)$.

Figure $8 E$ shows the latency of PSPs, again separated by motoneuron projection class. In all cases, latencies have been measured relative to the arrival of the afferent volley at the spinal segment (measured from the first inflection in the cord dorsum potential following the third stimulus). Nine of 23 IPSPs had latencies shorter than $2 \mathrm{~ms}$; this may indicate a disynaptic coupling or could reflect oligosynaptic input with responses beginning after the second stimulus in the train. There was a significant difference between the mean \pm SD latency of IPSPs and EPSPs $(2.89 \pm 1.7 \mathrm{~ms}$ and $5.6 \mathrm{~ms} \pm 3.1 \mathrm{~ms}$, respectively; $p<0.001$, unpaired $t$ test).

\section{Discussion}

\section{CINs in primate cervical cord}

In this report, we provide evidence for the existence of commissural premotor interneurons in the primate lower cervical enlargement. These target not only motoneurons of proximal muscles, where bilateral coordination might be expected for whole-body movements, but also those that innervate the intrinsic muscles of the hand, which are involved in more fractionated (but nonetheless bilaterally coordinated) voluntary movements.

Our main evidence for the existence of CINs is the demonstration that cISMS evokes short latency EPSPs and IPSPs motoneurons. Several alternative origins of these must be considered. First, it is important to exclude the possibility that cISMS did not spread to activate structures on the opposite side of the cord: this would have generated motoneuron responses via ipsilateral segmental, rather than commissural circuits. The extent of current spread depends on the activated structures (e.g., spiking thresholds for axons and cell bodies, which depend on their size and

\footnotetext{
$\leftarrow$

an intrinsic hand muscle (d), forearm flexor (f), forearm extensor (e), or a muscle proximal to the elbow (p). In cells that responded to multiple nerves, the earliest response has been used. $\boldsymbol{B}$ Same as in $A$, but now classified according to the contralateral nerve that evoked the response. CMN, Median at the arm; CUN, ulnar at the arm; CDRN, deep radial nerve. C, Venn diagram representation of responses to different contralateral nerves, compiled for motoneurons in which all three nerves were tested. $\boldsymbol{D}$, Amplitude of synaptic responses elicited by contralateral nerve stimulation, separated by motoneuron target muscle (same abbreviations as in $\boldsymbol{A}$ ). The different symbols correspond to the different contralateral nerves stimulated (see key); filled symbols represent IPSPs; and open symbols, EPSPs. Cross hairs to the right indicate mean \pm SD of amplitudes for the different $M N$ types. $\boldsymbol{E}$, Same as in $\boldsymbol{D}$, but plotting response latencies. Cross hairs to the right indicate the overall mean $\pm S D$ of EPSP and IPSP latencies. $\boldsymbol{D}, \boldsymbol{E}$, All observed responses, including cases where the same motoneuron responded to stimulation of more than one contralateral nerve.
} 
conduction velocity), and on the stimulus parameters (e.g., pulse width, current density). The current $I$ required to activate a neuron at a distance $r$ from the electrode tip increases as the square of the distance between the two:

$$
I=\mathrm{kr}^{2}
$$

where $k$ is the excitability constant in $\mu \mathrm{A} / \mathrm{mm}^{2}$ (Stoney et al., 1968; Nowak and Bullier, 1996). Estimates of $k$ vary widely for different cell populations, ranging from 2000 to $20,000 \mu \mathrm{A} / \mathrm{mm}^{2}$. Assuming a conservative $k$ value of 2000 and the maximum stimulation current, which we used of $300 \mu \mathrm{A}$, neural elements would be activated no more than $\sim 0.4 \mathrm{~mm}$ from the electrode tip. For 65 effects ( 13 of 15 of monosynaptic effects), the electrode tips used for cISMS were further from the midline than this value. More empirically, we implanted PT electrodes bilaterally in these experiments, with tips $0.3-2.2 \mathrm{~mm}$ from the midline. Using the same stimulating electrodes and stimulation parameters as for cISMS, we activated corticospinal axons unilaterally (Soteropoulos et al., 2011, their Fig. 1). Because corticospinal axons are among the largest and most excitable in the brain, it is unlikely that similar stimuli spread across the spinal midline to activate less excitable structures.

Our monosynaptic responses could have originated from activation (antidromic or orthodromic) of descending or propriospinal axons (Molenaar and Kuypers, 1978), both of which may send collaterals across the midline and contact motoneurons, as well as from activation of CINs. The corticospinal tract contains axons that synapse with motoneurons and axons that have commissural collaterals that terminate in lamina VIII of the cord, but it is not definitively known whether the same axons do both. Anatomical evidence suggests that those that synapse on motoneurons do not have collaterals that cross the midline (Shinoda et al., 1981; Lawrence et al., 1985). This is consistent with our results (Fig. 6), allowing us to exclude axon-reflex activation of corticospinal tract collaterals that both cross the midline and contact motoneurons as the source of these responses.

Descending fibers from the brainstem might also both cross the midline and contact motoneurons. Vestibulospinal pathways are unlikely to contribute to responses in distal motoneurons, but reticulospinal axons passing close to the MLF do have some connections with distal motoneurons (Riddle et al., 2009). There is evidence that some pontine reticulospinal axons have bilateral projections, although those that do tend to terminate in intermediate zone rather than motor nuclei (Matsuyama et al., 1997; Matsuyama et al., 1999).

Another potential origin of these effects is antidromic (rather than orthodromic) activation of CINs, which is possible if they also have collaterals to ipsilateral motoneurons. Information is incomplete, but the commissural neurons that have been studied either do not have ipsilateral collaterals or do not include the motor nuclei in their terminal areas (Bannatyne et al., 2003; Jankowska et al., 2009). The one exception is that some dorsal horn neurons with very widespread bilateral projections include the motor nuclei in their targets (Bannatyne et al., 2006), but these are exclusively inhibitory. Thus, antidromic activation of CINs with the properties of the studied known groups is unlikely to be the origin of the monosynaptic EPSPs. We can be less certain of the origin of the responses that have longer synaptic linkages.

The existence of CINs is further supported by the following: (1) the presence of PSPs evoked by stimulation of contralateral peripheral nerves because limb peripheral nerve afferents do not send collaterals across the spinal midline; and (2) evidence that the interaction of cISMS and MLF stimuli was able to facilitate responses to cISMS (Fig. 6), which is consistent with mediation by CINs with reticulospinal input like those described in the lumbar cord in the cat (Bannatyne et al., 2003). More recently, a transneuronal viral tracing study after injection of an intrinsic hand muscle reported secondorder neurons in the contralateral spinal cord, lending anatomical support to the existence of a commissural system connecting to distal limb motoneurons (Rathelot and Strick, 2010). Together, these findings provide strong evidence for the existence of spinal commissural neurons that connect with distal forelimb motoneurons, including intrinsic hand motoneurons.

Our recordings targeted motoneurons projecting to the forearm and hand, and our results therefore provide a picture of commissural connectivity mainly for muscles involved in hand and wrist movements. However, large and frequent synaptic responses to contralateral nerve stimulation were seen in all of the motoneurons identified as projecting to more proximal muscles (Fig. 8). It is likely that CINs will also provide input to muscles acting around the elbow and shoulder joints. Monosynaptic EPSPs elicited from cISMS were comparable in amplitude to those from cPT stimulation, whereas oligosynaptic cISMS effects were on average smaller. However, given the highly focal nature of the spinal cord stimulation (see above), it is unlikely that we could have activated more than a very small fraction of the CINs projecting to the recorded motoneuron. By contrast, $\mathrm{cPT}$ stimulation would activate a large fraction of the corticospinal axons. This suggests that CINs could be a potent source of input to primate forelimb motoneurons.

\section{Consequences for motor control of the primate forelimb}

Extensive prior work in cat lumbar cord has characterized several different groups of commissural neurons based on connectivity. In the present study, we establish the existence of commissural neurons in primate cervical cord, but our information on their inputs is fragmentary: some have input from fibers close to the MLF (Fig. 5), and the presence of PSPs in motoneurons elicited from contralateral peripheral nerves implies that CINs also receive sensory information.

The major spinal location for CINs is in the medial ventral horn, lamina VIII (e.g., see Harrison et al., 1986; Alstermark and Kummel, 1990; Bannatyne et al., 2003; Jankowska et al., 2009; Rathelot and Strick, 2010) This region is well known as a site of termination of brainstem descending fibers, such as the reticulospinal tract. It is also a major target for corticospinal axons that cross back to the side of their origin at spinal segmental level. Interestingly, Rosenzweig et al. (2010) recently demonstrated that, after unilateral spinal cord injury, corticospinal terminals on the spared side showed extensive sprouting caudal to the injury generating corticospinal collaterals that cross the midline. CINs could form a further route by which the spared corticospinal tract could influence contralateral spinal activity, as well as allowing integration with brainstem pathways, which also show postlesion plasticity (Zaaimi et al., 2012). CINs may thus form part of the neural circuits leading to functional recovery after lesion and could be a target for rehabilitative strategies that aim to optimize reorganization to improve functional recovery.

Commissural neurons are thought to coordinate movement based on peripheral afferent signals through crossed reflexes. There are few reports of previous tests for crossed reflex actions in the upper limb, in contrast to the more extensive literature in the lower limb (Gauthier and Rossignol, 1981; Fitzgerald, 1983; Eide et al., 1999; Jankowska et al., 2005b; Szokol et al., 2011). The available data show that crossed upper limb reflexes act to coor- 
dinate responses, not only across the midline but also between upper and lower limb in a task-dependent manner (Zehr et al., 2001; Zehr and Haridas, 2003).

Crossed spinal reflexes are usually thought of in terms of locomotor interlimb coordination (Duysens and Loeb, 1980; Gauthier and Rossignol, 1981; Gorassini et al., 1994; Hiebert et al., 1994) or the maintenance of posture (Roberts, 1978). Because macaques are quadrupedal, CINs in the cervical enlargement may play a similar role. Projections to the motoneurons of intrinsic hand muscles are not incompatible with a role in locomotion, during which the hands and digits must be accurately placed or used to grasp supports during climbing. However, an additional interesting possibility is that they may also contribute to the coordination of skilled bimanual movements associated with reaching and object manipulation, which are highly developed in primates. Almost all research on the neural substrates of bimanual coordination has focused on regions of cerebral cortex that are bilaterally organized or on coordination via the corpus callosum, which directly interconnects the two hemispheres. Despite the apparent prominence of this fiber tract, patients with complete callosal transections exhibit remarkably little deficit in well-learned everyday bimanual actions (Devinsky and Laff, 2003), and callosal connections for the hand representation of M1 are sparse (Rouiller et al., 1994). Multiple subcortical structures could allow the exchange of information across the midline, such as the reticular formation and cerebellum. Here we confirm that CINs in the cervical spinal cord could also play a role and may provide an evolutionarily "primitive" substrate on which primate cortical systems could act to mediate bilateral coordination.

\section{References}

Alstermark B, Kümmel H (1986) Transneuronal labelling of neurones projecting to forelimb motoneurones in cats performing different movements. Brain Res 376:387-391. CrossRef Medline

Alstermark B, Kümmel H (1990) Transneuronal transport of wheat germ agglutinin conjugated horseradish peroxidase into last order spinal interneurones proejcting to acromio- and spinodeltoideus motoneurones in the cat: 1. Location of labelled interneurones and influence of synaptic activity on the transneuronal transport. Exp Brain Res 80:83-95. CrossRef Medline

Aoyama M, Hongo T, Kudo N, Tanaka R (1971) Convergent effects from bilateral vestibulospinal tracts on spinal interneurons. Brain Res 35:250253. CrossRef Medline

Bajwa S, Edgley SA, Harrison PJ (1992) Crossed actions on group IIactivated interneurones in the midlumbar segments of the cat spinal cord. J Physiol 455:205-217. Medline

Bannatyne BA, Edgley SA, Hammar I, Jankowska E, Maxwell DJ (2003) Networks of inhibitory and excitatory commissural interneurons mediating crossed reticulospinal actions. Eur J Neurosci 18:2273-2284. CrossRef Medline

Bannatyne BA, Edgley SA, Hammar I, Jankowska E, Maxwell DJ (2006) Differential projections of excitatory and inhibitory dorsal horn interneurons relaying information from group II muscle afferents in the cat spinal cord. J Neurosci 26:2871-2880. CrossRef Medline

Bannatyne BA, Liu TT, Hammar I, Stecina K, Jankowska E, Maxwell DJ (2009) Excitatory and inhibitory intermediate zone interneurons in pathways from feline group I and II afferents: differences in axonal projections and input. J Physiol 587:379-399. CrossRef Medline

Brinkman J, Kuypers HG (1973) Cerebral control of contralateral and ipsilateral arm, hand and finger movements in the split-brain Rhesus monkey. Brain 96:653-674. CrossRef Medline

Buford JA, Davidson AG (2004) Movement-related and preparatory activity in the reticulospinal system of the monkey. Exp Brain Res 159:284-300. CrossRef Medline

Carleton SC, Carpenter MB (1983) Afferent and efferent connections of the medial, inferior and lateral vestibular nuclei in the cat and monkey. Brain Res 278:29-51. CrossRef Medline

Devinsky O, Laff R (2003) Callosal lesions and behavior: history and modern concepts. Epilepsy Behav 4:607-617. CrossRef Medline
Donchin O, Gribova A, Steinberg O, Mitz AR, Bergman H, Vaadia E (2002) Single-unit activity related to bimanual arm movements in the primary and supplementary motor cortices. J Neurophysiol 88:3498-3517. CrossRef Medline

Duysens J, Loeb GE (1980) Modulation of ipsi- and contralateral reflex responses in unrestrained walking cats. J Neurophysiol 44:1024-1037. Medline

Edgley SA, Jankowska E, Krutki P, Hammar I (2003) Both dorsal horn and lamina VIII interneurones contribute to crossed reflexes from feline group II muscle afferents. J Physiol 552:961-974. CrossRef Medline

Edgley SA, Jankowska E, Hammar I (2004) Ipsilateral actions of feline corticospinal tract neurons on limb motoneurons. J Neurosci 24:7804-7813. CrossRef Medline

Eide AL, Glover J, KjaerulffO, Kiehn O (1999) Characterization of commissural interneurons in the lumbar region of the neonatal rat spinal cord. J Comp Neurol 403:332-345. CrossRef Medline

Eliassen JC, Baynes K, Gazzaniga MS (2000) Anterior and posterior callosal contributions to simultaneous bimanual movements of the hands and fingers. Brain 123:2501-2511. CrossRef Medline

Endo K, Kasper J, Wilson VJ, Yates BJ (1994) Response of commissural and other upper cervical ventral horn neurons to vestibular stimuli in vertical planes. J Neurophysiol 71:11-16. Medline

Fitzgerald M (1983) Influences of contralateral nerve and skin stimulation on neurones in the substantia gelatinosa of the rat spinal cord. Neurosci Lett 36:139-143. CrossRef Medline

Fukushima K, Peterson BW, Wilson VJ (1979) Vestibulospinal, reticulospinal and interstitiospinal pathways in the cat. Prog Brain Res 50:121-136. CrossRef Medline

Gauthier L, Rossignol S (1981) Contralateral hindlimb responses to cutaneous stimulation during locomotion in high decerebrate cats. Brain Res 207:303-320. CrossRef Medline

Gorassini MA, Prochazka A, Hiebert GW, Gauthier MJ (1994) Corrective responses to loss of ground support during walking: I. Intact cats. J Neurophysiol 71:603-610. Medline

Hammar I, Bannatyne BA, Maxwell DJ, Edgley SA, Jankowska E (2004) The actions of monoamines and distribution of noradrenergic and serotoninergic contacts on different subpopulations of commissural interneurons in the cat spinal cord. Eur J Neurosci 19:1305-1316. CrossRef Medline

Hammar I, Stecina K, Jankowska E (2007) Differential modulation by monoamine membrane receptor agonists of reticulospinal input to lamina VIII feline spinal commissural interneurons. Eur J Neurosci 26:12051212. CrossRef Medline

Harrison PJ, Jankowski D, Zytnicki D (1986) Transneural labeling of neurons projecting to forelimb motoneurons in cats performing different movements. Brain Res 376:387-391. Medline

Hiebert GW, Gorassini MA, Jiang W, Prochazka A, Pearson KG (1994) Corrective responses to loss of ground support during walking: II. Comparison of intact and chronic spinal cats. J Neurophysiol 71:611-622. Medline

Jankowska E (2008) Spinal interneuronal networks in the cat: elementary components. Brain Res Rev 57:46-55. CrossRef Medline

Jankowska E, Hammar I, Slawinska U, Maleszak K, Edgley SA (2003) Neuronal basis of crossed actions from the reticular formation on feline hindlimb motoneurons. J Neurosci 23:1867-1878. Medline

Jankowska E, Krutki P, Matsuyama K (2005a) Relative contribution of Ia inhibitory interneurones to inhibition of feline contralateral motoneurones evoked via commissural interneurones. J Physiol 568:617-628. CrossRef Medline

Jankowska E, Edgley SA, Krutki P, Hammar I (2005b) Functional differentiation and organization of feline midlumbar commissural interneurones. J Physiol 565:645-658. CrossRef Medline

Jankowska E, Stecina K, Cabaj A, Pettersson LG, Edgley SA (2006) Neuronal relays in double crossed pathways between feline motor cortex and ipsilateral hindlimb motoneurones. J Physiol 575:527-541. CrossRef Medline

Jankowska E, Bannatyne BA, Stecina K, Hammar I, Cabaj A, Maxwell DJ (2009) Commissural interneurons with input from group I and II muscle afferents in feline lumbar segments: neurotransmitters, projections and target cells. J Physiol 587:401-418. CrossRef Medline

Kazennikov O, Hyland B, Corboz M, Babalian A, Rouiller EM, Wiesendanger M (1999) Neural activity of supplementary and primary motor areas in monkeys and its relation to bimanual and unimanual movement sequences. Neuroscience 89:661-674. CrossRef Medline

Kennerley SW, Diedrichsen J, Hazeltine E, Semjen A, Ivry RB (2002) Callo- 
sotomy patients exhibit temporal uncoupling during continuous bimanual movements. Nat Neurosci 5:376-381. CrossRef Medline

Kermadi I, Liu Y, Rouiller EM (2000) Do bimanual motor actions involve the dorsal premotor $(\mathrm{PMd})$, cingulate $(\mathrm{CMA})$ and posterior parietal (PPC) cortices? Comparison with primary and supplementary motor cortical areas. Somatosens Mot Res 17:255-271. CrossRef Medline

Lawrence DG, Porter R, Redman SJ (1985) Corticomotoneuronal synapses in the monkey: light microscopic localization upon motoneurons of intrinsic muscles of the hand. J Comp Neurol 232:499-510. CrossRef Medline

Matsuyama K, Takakusaki K, Nakajima K, Mori S (1997) Multi-segmental innervation of single pontine reticulospinal axons in the cervico-thoracic region of the cat: anterograde PHA-L tracing study. J Comp Neurol 377: 234-250. CrossRef Medline

Matsuyama K, Mori F, Kuze B, Mori S (1999) Morphology of single pontine reticulospinal axons in the lumbar enlargement of the cat: a study using the anterograde tracer PHA-L. J Comp Neurol 410:413-430. CrossRef Medline

Mitani A, Ito K, Mitani Y, McCarley RW (1988) Descending projections from the gigantocellular tegmental field in the cat: cells of origin and their brainstem and spinal cord trajectories. J Comp Neurol 268:546-566. CrossRef Medline

Molenaar I, Kuypers HG (1978) Cells of origin of propriospinal fiber and fibers ascending to supraspinal levels: an HRP study in cat and rhesus monkey. Brain Res 152:429-450. CrossRef Medline

Nowak LG, Bullier J (1996) Spread of stimulating current in the cortical grey matter of rat visual cortex studied on a new in vitro slice preparation. J Neurosci Methods 67:237-248. CrossRef Medline

Peterson BW (1979) Reticulospinal projections to spinal motor nuclei. Annu Rev Physiol 41:127-140. CrossRef Medline

Peterson BW, Maunz RA, Pitts NG, Mackel RG (1975) Patterns of projection and branching of reticulospinal neurons. Exp Brain Res 23:333-351. CrossRef Medline

Peterson BW, Pitts NG, Fukushima K (1979) Reticulospinal connections with limb and axial motoneurons. Exp Brain Res 36:1-20. CrossRef Medline

Prentice SD, Drew T (2001) Contributions of the reticulospinal system to the postural adjustments occurring during voluntary gait modifications. J Neurophysiol 85:679-698. Medline

Rathelot JA, Strick PL (2010) Last-order interneurons innervating forelimb motoneurons in the spinal cord of the monkey. Society for Neurosciences, p 494. San Diego.

Riddle CN, Baker SN (2010) Convergence of pyramidal and medial brain stem descending pathways onto macaque cervical spinal interneurons. J Neurophysiol 103:2821-2832. CrossRef Medline

Riddle CN, Edgley SA, Baker SN (2009) Direct and indirect connections with upper limb motoneurons from the primate reticulospinal tract. J Neurosci 29:4993-4999. CrossRef Medline

Roberts TDM (1978) Neurophysiology of postural mechanisms. London: Butterworth.

Rosenzweig ES, Brock JH, Culbertson MD, Lu P, Moseanko R, Edgerton VR, Havton LA, Tuszynski MH (2009) Extensive spinal decussation and bilateral termination of cervical corticospinal projections in rhesus monkeys. J Comp Neurol 513:151-163. CrossRef Medline

Rosenzweig ES, Courtine G, Jindrich DL, Brock JH, Ferguson AR, Strand SC, Nout YS, Roy RR, Miller DM, Beattie MS, Havton LA, Bresnahan JC, Edgerton VR, Tuszynski MH (2010) Extensive spontaneous plasticity of corticospinal projections after primate spinal cord injury. Nat Neurosci 13:1505-1510. CrossRef Medline

Rouiller EM, Babalian A, Kazennikov O, Moret V, Yu XH, Wiesendanger M (1994) Transcallosal connections of the distal forelimb representations of the primary and supplementary motor cortical areas in macaque monkeys. Exp Brain Res 102:227-243. CrossRef Medline
Schepens B, Drew T (2004) Independent and convergent signals from the pontomedullary reticular formation contribute to the control of posture and movement during reaching in the cat. J Neurophysiol 92:2217-2238. CrossRef Medline

Schepens B, Drew T (2006) Descending signals from the pontomedullary reticular formation are bilateral, asymmetric, and gated during reaching movements in the cat. J Neurophysiol 96:2229-2252. CrossRef Medline

Serrien DJ, Nirkko AC, Wiesendanger M (2001) Role of the corpus callosum in bimanual coordination: a comparison of patients with congenital and acquired callosal damage. Eur J Neurosci 14:1897-1905. CrossRef Medline

Shinoda Y, Yokota J, Futami T (1981) Divergent projection of individual corticospinal axons to motoneurons of multiple muscles in the monkey. Neurosci Lett 23:7-12. CrossRef Medline

Shinoda Y, Ohgaki T, Futami T (1986) The morphology of single lateral vestibulospinal tract axons in the lower cervical spinal cord of the cat. J Comp Neurol 249:226-241. CrossRef Medline

Soteropoulos DS, Baker SN (2006) Cortico-cerebellar coherence during a precision grip task in the monkey. J Neurophysiol 95:1194-1206. CrossRef Medline

Soteropoulos DS, Baker SN (2007) Different contributions of the corpus callosum and cerebellum to motor coordination in monkey. J Neurophysiol 98:2962-2973. CrossRef Medline

Soteropoulos DS, Baker SN (2008) Bilateral representation in the deep cerebellar nuclei. J Physiol 586:1117-1136. CrossRef Medline

Soteropoulos DS, Edgley SA, Baker SN (2011) Lack of evidence for direct corticospinal contributions to control of the ipsilateral forelimb in monkey. J Neurosci 31:11208-11219. CrossRef Medline

Soteropoulos DS, Williams ER, Baker SN (2012) Cells in the monkey pontomedullary reticular formation modulate their activity with slow finger movements. J Physiol 590:4011-4027. CrossRef Medline

Spidalieri G, Guandalini P, Franchi G (1986) Motor responses mediated by orthodromic and antidromic activation of the rostral portion of the cat corpus callosum. Exp Brain Res 64:133-142. CrossRef Medline

Stecina K, Jankowska E, Cabaj A, Pettersson LG, Bannatyne BA, Maxwell DJ (2008) Premotor interneurones contributing to actions of feline pyramidal tract neurones on ipsilateral hindlimb motoneurones. J Physiol 586: 557-574. CrossRef Medline

Stoney SD Jr, Thompson WD, Asanuma H (1968) Excitation of pyramidal tract cells by intracortical microstimulation: effective extent of stimulating current. J Neurophysiol 31:659-669. Medline

Sugiuchi Y, Kakei S, Shinoda Y (1992) Spinal commissural neurons mediating vestibular input to neck motoneurons in the cat upper cervical spinal cord. Neurosci Lett 145:221-224. CrossRef Medline

Szokol K, Glover JC, Perreault MC (2011) Organization of functional synaptic connections between medullary reticulospinal neurons and lumbar descending commissural interneurons in the neonatal mouse. J Neurosci 31:4731-4742. CrossRef Medline

Tanji J, Okano K, Sato KC (1988) Neuronal activity in cortical motor areas related to ipsilateral, contralateral, and bilateral digit movements of the monkey. J Neurophysiol 60:325-343. Medline

Zaaimi B, Edgley SA, Soteropoulos DS, Baker SN (2012) Changes in descending motor pathway connectivity after corticospinal tract lesion in macaque monkey. Brain 135:2277-2289. CrossRef Medline

Zehr EP, Haridas C (2003) Modulation of cutaneous reflexes in arm muscles during walking: further evidence of similar control mechanisms for rhythmic human arm and leg movements. Exp Brain Res 149:260-266. CrossRef Medline

Zehr EP, Collins DF, Chua R (2001) Human interlimb reflexes evoked by electrical stimulation of cutaneous nerves innervating the hand and foot. Exp Brain Res 140:495-504. CrossRef Medline 